\title{
Computational Fluid Dynamics Modeling of Steam Condensation on Nuclear Containment Wall Surfaces Based on Semiempirical Generalized Correlations
}

\author{
Pavan K. Sharma, B. Gera, R. K. Singh, and K. K. Vaze \\ Reactor Safety Division, Bhabha Atomic Research Centre, Engg. Hall-7, Trombay, Mumbai 400085, India \\ Correspondence should be addressed to Pavan K. Sharma, pa1.sharma@gmail.com
}

Received 12 May 2011; Revised 22 September 2011; Accepted 28 September 2011

Academic Editor: Leon Cizelj

Copyright (C) 2012 Pavan K. Sharma et al. This is an open access article distributed under the Creative Commons Attribution License, which permits unrestricted use, distribution, and reproduction in any medium, provided the original work is properly cited.

In water-cooled nuclear power reactors, significant quantities of steam and hydrogen could be produced within the primary containment following the postulated design basis accidents (DBA) or beyond design basis accidents (BDBA). For accurate calculation of the temperature/pressure rise and hydrogen transport calculation in nuclear reactor containment due to such scenarios, wall condensation heat transfer coefficient (HTC) is used. In the present work, the adaptation of a commercial CFD code with the implementation of models for steam condensation on wall surfaces in presence of noncondensable gases is explained. Steam condensation has been modeled using the empirical average HTC, which was originally developed to be used for "lumpedparameter" (volume-averaged) modeling of steam condensation in the presence of noncondensable gases. The present paper suggests a generalized HTC based on curve fitting of most of the reported semiempirical condensation models, which are valid for specific wall conditions. The present methodology has been validated against limited reported experimental data from the COPAIN experimental facility. This is the first step towards the CFD-based generalized analysis procedure for condensation modeling applicable for containment wall surfaces that is being evolved further for specific wall surfaces within the multicompartment containment atmosphere.

\section{Introduction}

Steam condensation in the presence of noncondensable gases is a relevant phenomenon in many industrial applications, including nuclear reactors. Condensation on the containment structures during an accident and associated computations are important for the containment design of all the existing reactors for LOCA DBA, DBA, and BDBA hydrogen distribution and recombination and passive emergency systems in the nuclear reactors of new generation. Rate of steam condensation at containment walls affects the transient pressure in the containment after loss of coolant accident. Apart from this during a severe accident in a water-cooled power reactor nuclear power plant (NPP), large amounts of hydrogen would presumably be generated due to core degradation and released into the containment. The integrity of the containment could be threatened due to hydrogen combustion.
If composition of the hydrogen-steam-air mixture lies within a certain limits, the combustion will occur. The steam condensation phenomenon is important from hydrogen distribution point of view to locate the flammable region in the containment for adequate accident management procedures (Royl et al., 2000 [1]).

Currently use of CFD techniques to model such scenario is popular, since CFD codes provide more detailed information in such scenario. These commercially available CFD codes generally do not have built-in steam condensations models. Consequently, it is necessary to implement steam condensation via user-defined subroutines. Two main approaches have been proposed by various authors to model wall condensation in CFD codes. In the first approach (twophase flow approach) separate momentum equations are solved for vapour and liquid phases. A fine mesh is required, and liquid film and the diffusion of steam towards wall 
through boundary layer formed by noncondensable gases are modeled. This approach is quite close to first-principle condensation modeling but requires very large computational time and will probably take some time to be used for any practical applications (full containment modeling) in future. In the second approach a single-fluid model is used where steam is modeled as a separate species via species conservation equation. For modeling steam condensation, mass sink and corresponding energy sink are modeled in the very first cell near to condensing wall. In this second approach there are two ways to calculate these sink terms. The first one is based on diffusion theory which requires a very fine mesh near the wall and computes steam condensation rate that diffuses towards wall through species boundary layer. Houkema et al., in 2008, [2] have used this approach without the use of engineering correlations for steam condensation on walls. Babić et al., 2008 [3], Kljenak et al., 2006 [4], and Kljenak et al., 2004 [5], have used individual HTCbased approach with CFD code CFX to simulate experiments on containment atmosphere behavior at accident conditions, which were performed in the TOSQAN and ThAI experimental facilities. Currently the most popular way is to include heat or mass transfer correlations that were originally developed for "lumped-parameter" (volumeaveraged) calculations and apply them in the layer of cells contiguous to the condensation surface. These correlations use the temperature and steam mass fraction value from bulk flow and calculate the condensing heat transfer coefficient, since the corresponding sink term is applied for the very first fluid cell near the condensing wall, and the bulk flow parameters and thermophysical properties are evaluated at these cell centres. Thus in this approach rate of heat and mass transfer depends on the cell width near the condensing wall. CFD codes were developed to solve equations that are derived from the first principles, using local instantaneous description, so that the inclusions of correlations, which are based on averaged physical quantities and provide average condensation rates, are somehow contrary to the basic "philosophy" of CFD (Kljenak et al., 2006 [4]).

Wide ranges of HTCs have been reported which have come from condensation experimental setup largely different from actual containment accident situation during accident. Uses of the so-called conservative (safe values in context of peak pressure, temperature, or hydrogen concentration, etc.) individual HTC also have conflicting position in respect of containment pressure transient calculation and hydrogen distribution/management calculation. An HTC value which results in lower condensation of steam gives conservative results for containment pressure calculation, but gives nonconservative results for hydrogen management calculation due to artificial inerting atmosphere because of less condensation of steam. Authors try to overcome this weakness by trying to use many empirical correlations and theoretical calculations by making a generalized HTC from most of the generally reported approaches. The present combined approach allows relatively fast calculations and should be adequate for large industrial applications.

Steam condensation was modeled as a sink of mass and enthalpy by applying the correlation by Uchida et al., 1965
[6]. Valdepenas et al., 2007 [7], have also used the second approach for modeling steam condensation on walls where condensation rate was based on correlation developed by Terasaka and Makita, 1997 [8]. Mimouni et al., 2010 [9], have modeled steam condensation by a two-phase flow approach that takes into account the physical phenomena of importance like effect of liquid film thickness. In the CFD code TONUS developed for hydrogen risk analysis (Kudriakov et al., 2008 [10]), steam condensation was implemented as steam diffusion through a mass boundary layer based on heat and mass transfer analogy (Chilton-Colburn type).

The present paper is about development and comparison of the wall condensation model based on semiempirical correlation (existing and proposed based on curve fit of various existing correlations) in CFD-ACE+ [11]. The implemented condensation model will be described, and results of validation calculations are compared with experimental data. A brief overview will be given on the comparison of results obtained with CFD-ACE+ versus experimental results from COPAIN test facility. The simulation was performed with the knowledge of experimental results.

\section{Condensation for Containment Thermal Hydraulics for Practical Applications}

Review papers on condensation on the containment structures (Green and Almenas, 1996 [12], Rosa et al., 2009 [13]) enlist the various parameter of interest, that is, subcooling, interfacial shear, superheating, difference of temperatures, noncondensables gases, lighter gases, effect of pressure, effect of velocity, density difference between bulk and interface, leaning of the surface, length of the surface, and so forth, mostly for average heat transfer coefficient. Some other parameters which affect the containment condensation are the material of wall, structure porosity, wettability, use of epoxy paints, effect of aerosol, and so forth. In the context of average heat transfer coefficient, the dimension of the test setup at which the coefficient is experimentally derived is also an important factor which can be in the form of volume scaling in context of energy addition from hot steam and height scaling in context of buoyancy (both due to temperature and concentration density gradient). The authors have plotted most of the reported empirical correlations from the literature. Several of such HTCs have been used in lumpedparameter-and CFD-based analysis. Table 1 compiles few other reported empirical HTC.

The major limitations for individual HTC use in CFD codes which have been mentioned earlier come from the fact that, the use of global correlation as the local one, different length and energy addition/removal time scales, modeling of surface condensation phenomenon as volume phenomena, different reported range of experimental parameters like size, flow regimes of convection, type and quantity of combustible, type of walls, configuration of wall (mostly pipes), and so forth. Some of the HTCs are plotted in Figure 1 by taking parameters from the Copain experiment (described later in the paper) data especially the temperature difference between wall and the bulk mixture along with pressure values. 
TABLE 1: Review of containment-specific steam condensation HTC.

\begin{tabular}{|c|c|c|}
\hline S. no. & Name & Equation \\
\hline 1 & Uchida (Rosa et al., 2009 [13]) & $h=380 \eta^{-0.7}, h\left(\mathrm{~W} / \mathrm{m}^{2}\right)$ \\
\hline 2 & Tagami steady state (Rosa et al., 2009 [13]) & $h=11.4+284(\eta /(1-\eta)), h\left(\mathrm{~W} / \mathrm{m}^{2}\right)$ \\
\hline 3 & Debhi (Rosa et al., 2009 [13]) & $\begin{array}{l}h=L^{0.05}[(3.7+28.0 P)-(243.8+458.3 P) \log \eta] /\left(\left(T_{b}-T_{w}\right)^{0.25}\right), \\
h\left(\mathrm{~W} / \mathrm{m}^{2}\right), P(\mathrm{Atm}), L(\mathrm{~m}), T(\mathrm{~K})\end{array}$ \\
\hline 4 & Kataoka (Rosa et al., 2009 [13]) & $h=430 \eta^{-0.8}, h\left(\mathrm{~W} / \mathrm{m}^{2}\right)$ \\
\hline 5 & Murase (Rosa et al., 2009 [13]) & $h=0.47 \eta^{-1.0}, h\left(\mathrm{~W} / \mathrm{m}^{2}\right)$ \\
\hline 6 & Liu (Lee and Kim, 2008 [14]) & $h=55.635(1-\eta)^{2.344} P^{0.252}\left(\left(T_{b}-T_{w}\right)^{0.307}\right), h\left(\mathrm{~W} / \mathrm{m}^{2}\right), P(\mathrm{~Pa}), T(\mathrm{~K})$ \\
\hline 7 & Green (Green and Almenas, 1996 [12]) & $h=316 \eta^{-0.86}\left(\left(T_{b}-T_{w}\right)^{-0.15}\right), h\left(\mathrm{~W} / \mathrm{m}^{2}\right), T(\mathrm{~K})$ \\
\hline 8 & Kawakubo (Kawakubo et al., 2009 [15]) & $\begin{array}{l}h=\min \left(0.33 \eta^{-0.8} \times\left(T_{b}-T_{w}\right)^{0.25}, \eta^{-1.0} \times\left(T_{b}-T_{w}\right)^{-0.22 \eta^{-0.25}}\right) \times(P+0.5), \\
h\left(\mathrm{Kw} / \mathrm{m}^{2}\right), P(\mathrm{MPa})\end{array}$ \\
\hline 9 & Nusselt UCB Multiplier (Park et al., 1999 [16]) & $\begin{array}{l}h=f_{1} \times f_{2} \times h_{\text {nusselt }} \text { where } f_{2}=\left(1+2.88 E^{-05} \mathrm{Re}_{\text {mix }}^{1.18}\right) \text { and a maximum fixed } \\
\text { value of } 2.0 \text { is used in present paper. } h\left(\mathrm{~W} / \mathrm{m}^{2}\right) \\
h_{\text {nusselt }}=k_{f} / \delta \text { and } f_{2}=(1-10.0 \eta) \text { for } \eta<0.063 \\
f_{2}=\left(1-0.938 \eta^{0.13}\right) \text { for } 0.063<\eta<0.6 \\
f_{2}=\left(1-\eta^{0.22}\right) \text { for } \eta>0.6\end{array}$ \\
\hline 10 & Nusselt LEE Multiplier (Lee and Kim, 2008 [14]) & $\begin{array}{l}h=f_{\text {lee }} \times h_{\text {nusselt }} \text { where } \\
h_{\text {nusselt }}=k_{f} / \delta \text { and } f_{\text {lee }}=\tau_{\text {mix }}{ }^{0.3124}\left(1-0.964 \eta^{0.402}\right), h\left(\mathrm{~W} / \mathrm{m}^{2}\right)\end{array}$ \\
\hline 11 & Proposed fit from all the curves & $h=3522.70-14324.78 \eta+22090.84 \eta^{2}+11393.13 \eta^{3}, h\left(\mathrm{~W} / \mathrm{m}^{2}\right)$ \\
\hline
\end{tabular}

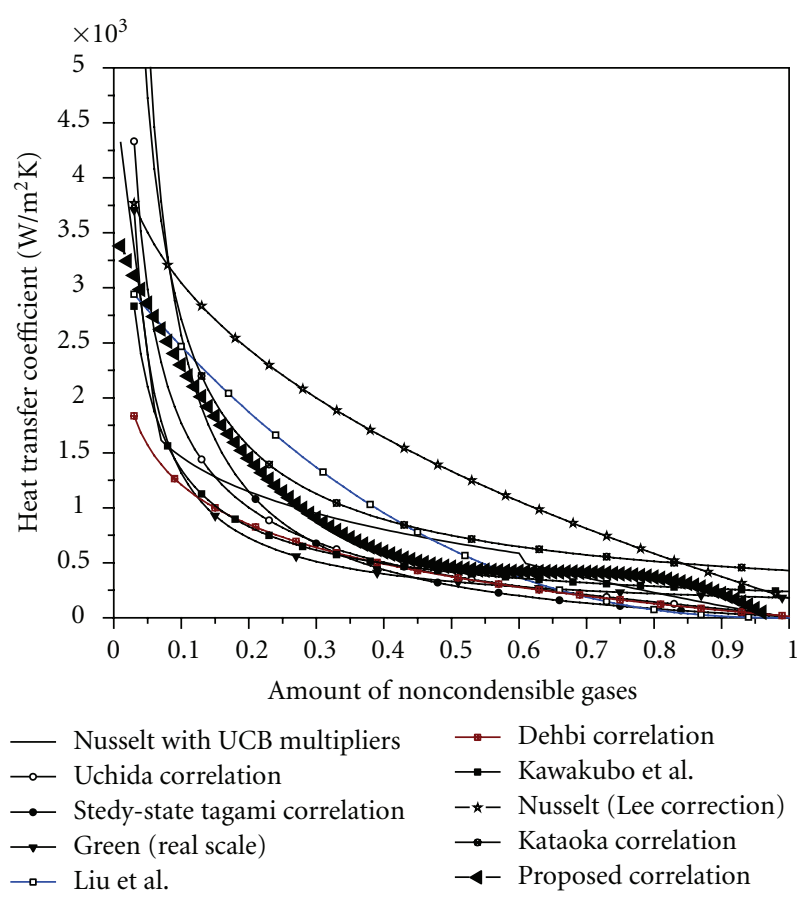

Figure 1: Various HTCs from the literature and proposed HTC based on curve fitting.

The classical Nusselt theory gives the HTC as the conductivity of the liquid film divided by the film thickness, so the classical HTC will be a fixed value. Subsequently Nusselt theory gets modified with the use of two multipliers (UCB multipliers): first one takes care of enhancement of the HTC due to liquid film shearing and the associated effects, and the second multiplier takes care of the degradation of the HTC due to presence of non condensable gases. Authors have also suggested and used the multiplier developed by Lee and Kim, 2008 [14], to modify the Nusselt HTC. The compilation of all such correlations, from various experimental correlations along with the classical Nusselt theory, Nusselt USB correlation and the almost real scale HDR test setup based on Green's HTC is depicted in Figure 1. In real situations for HDR, HTC is normally less as compared to the experimental scale and conditions.

Another issue is about the conservatism of the HTC in nuclear regulatory organization suggesting HTC and practical HTC due to large variations in reported values. We use a correlation with small HTC value (being conservative) for containment pressure and temperature calculation which will result in higher containment peak pressure values. But the same conservatism aspect may not be valid for hydrogen distribution in the reactor containment atmosphere as higher pressure differences in multiple-compartment configurations will result in increased intercompartmental mixing and reduction in hydrogen concentration. The lower HTC may also result in relatively uniform temperature field which will decrease the amount of hydrogen stratification due to buoyancy and also results in lower hydrogen concentration values. A lower HTC gives non-conservative results for hydrogen management calculation due to artificial inerting atmosphere due to low condensation of steam. Another issue of bias for use in the lower HTC values was with regard to the earlier correlations developed for low velocity of steam and calm and undisturbed atmosphere. The actual accident scenario may have more turbulent flow dynamics. In real accident situation the accident conditions will be very complex and uncertain. The most logical approach could be to fit a curve from all the possible HTC correlations for the most 
dominating parameter of interest, that is, amount of non condensable gases. A finite film of preidentified thickness is always assumed to be sticking to the wall.

\section{Mathematical Model}

The general-purpose CFD code CFD-ACE+ solves the local instantaneous transport equations for mass, momentum, energy, species, and turbulence parameters. The general transport equation for variable $\phi$ is

$$
\frac{\partial(\rho \phi)}{\partial t}+\frac{\partial\left(\rho u_{i} \phi\right)}{\partial x_{i}}=\frac{\partial}{\partial x_{i}}\left(\Gamma_{\phi} \frac{\partial \phi}{\partial x_{i}}\right)+S_{\phi},
$$

where $\phi$ is appropriate variable (mass, momentum, energy, species, and turbulence parameters), $\Gamma_{\phi}$ is diffusion coefficient and $S_{\phi}$ is the sink or source term. To model the mixture behaviour of air and steam, an approach where only one velocity field was defined using the average density of gas mixture was used. The independent behaviour of steam was considered using species transport equation. The discretisation of the equations in the CFD-ACE+ code is based on a conservative finite-volume method. A nonstaggered grid arrangement is employed, where all the variables (velocity components and scalars) are stored in the geometrical centers of control volumes (cells) that fill up the flow domain.

In the present work steam condensation was modeled as a sink for mass and enthalpy by applying the empirical correlation based on experiments on forced convection and implemented in a subroutine. The condensate film on structures was considered to have a fixed thickness. Basically, the steam condensation rate was obtained from the expression

$$
m^{0}=\mathrm{HTC} \frac{A\left(T-T_{\mathrm{wall}}\right)}{h_{f g}} .
$$

In this correlation, values of all the physical variables were required from bulk flow except $T_{\text {wall }}$ which was the condensing wall temperature. This correlation will always predict the condensation as long as bulk temperature is more than wall temperatures even if the steam partial pressure is lower than the saturation pressure at the condensing wall temperature. The steam partial pressure must be higher than the saturation pressure at the temperature of the wall for condensation to occur; this was ensured by applying the appropriate condition in user-defined subroutine. Thus, during the simulation, the amount of steam condensation was calculated only if the steam partial pressure was above the saturation pressure. The corresponding enthalpy sink $H^{0}$ (sink term in energy flow equation) due to condensation was calculated as follows:

$$
H^{0}=m^{0}\left(C_{p \text {,steam }} T_{\text {cell }}-C_{p, \text { air }} T_{\text {ref }}\right) .
$$

The specific heat of the air and reference temperature $T_{\text {ref }}$ was used for calculation of reference enthalpy in the CFD-ACE+ code. A user-defined subroutine was added for modeling steam condensation as sinks of mass and enthalpy were identified in cells contiguous to the condensing wall in the CFD-ACE+ computational tool. The mass sink was calculated from (2) for each cell where the "bulk flow" physical quantities (temperature, steam density, and noncondensible gas density) were evaluated at the cell centre. As the temperature of the gaseous mixture corresponding to the cell centre appears in (2) and (3), the calculated condensation rate and enthalpy sink necessarily depend on the width of cells contiguous to the condensation surface (Kljenak et al., 2006 [4]). The saturation pressure at condensing wall temperature was calculated, and it was ensured that steam partial pressure must be higher than the saturation pressure at the temperature of the wall for condensation to occur. The Antoine equation is used to describe the vapour pressure as a function of the surface temperature:

$$
\ln \left(\frac{P}{1 \mathrm{~Pa}}\right)=B+\frac{C}{T+D}
$$

The coefficients $B, C$, and $D$ were fitted based on data from steam tables, and the values used were $B=+23.1512, C=$ $-3788.02 \mathrm{~K}$, and $D=-47.3018 \mathrm{~K}$. It was assumed that the condensing wall immediately removes the condensation heat. The air steam mixture was considered compressible, and density was modeled by ideal gas law. Standard k- $\varepsilon$ model with standard wall function was used for modeling turbulence in all the simulation due to its wide use and acceptance in industrial applications. The use of standard wall functions is justified as the present condensation modeling is not from the first principle and not sensitive to the wall function.

\section{COPAIN Experimental Facility}

The COPAIN experimental facility (CEA, Grenoble) Cheng et al., 2001 [17] was a simple facility designed to study the phenomenon of wall condensation in the presence of noncondensible gases. The facility consists of a vertically placed rectangular channel of cross-section $0.6 \mathrm{~m} \times 0.5 \mathrm{~m}$. The vertical height is around $2.5 \mathrm{~m}$ where one vertical side served as a condensation plate up to $2 \mathrm{~m}$ height. The experiments were reported to be performed with pressure between 1 and 7 bar $(100-700 \mathrm{kPa})$, temperature under $165^{\circ} \mathrm{C}$, heat flux exchange with the plate between 1 and $30 \mathrm{~kW} / \mathrm{m}^{2}$, and maximum inwards velocity of $3 \mathrm{~m} / \mathrm{s}$, with different fraction of air, steam, and, helium. Inside the channel forced or natural convection was observed depending on prevailing conditions. The database selected to validate the wall condensation model is shown in Table 2 for various experiments. The full computational domain was simulated. A fine mesh was made with 93750 cells so that average cell size near the wall is $0.02 \mathrm{~m}$ as suggested by different authors (Babić et al., 2008 [3], Kljenak et al., 2006 [4]). The grids were uniform, including the nearest cells to the wall. In this simulation, the condensation acts as a sink of mass and energy. Thus, the liquid film and the influence of the noncondensible gas layer were reduced to a simple sink term. 
TABle 2: Parameters of the COPAIN tests.

\begin{tabular}{lcccccc}
\hline Test no. & $\begin{array}{c}\text { Convective heat } \\
\text { transfer }\end{array}$ & $\begin{array}{c}\text { Air velocity at inlet } \\
(\mathrm{m} / \mathrm{s})\end{array}$ & $\begin{array}{c}\text { Pressure } \\
(\mathrm{bar})\end{array}$ & $\begin{array}{c}\text { Air temperature at inlet } \\
(\mathrm{K})\end{array}$ & $\begin{array}{c}\text { Wall temperature } \\
(\mathrm{K})\end{array}$ & $\begin{array}{c}\text { Mass fraction of } \\
\text { noncondensible gases }\end{array}$ \\
\hline P0441 & Forced & 3 & 1.02 & 353.23 & 307.4 & 0.767 \\
P0443 & Free & 1 & 1.02 & 352.33 & 300.06 & 0.772 \\
P0444 & Natural & 0.5 & 1.02 & 351.53 & 299.7 & 0.773 \\
P0344 & Natural & 0.3 & 1.21 & 344.03 & 322 & 0.864 \\
\hline
\end{tabular}

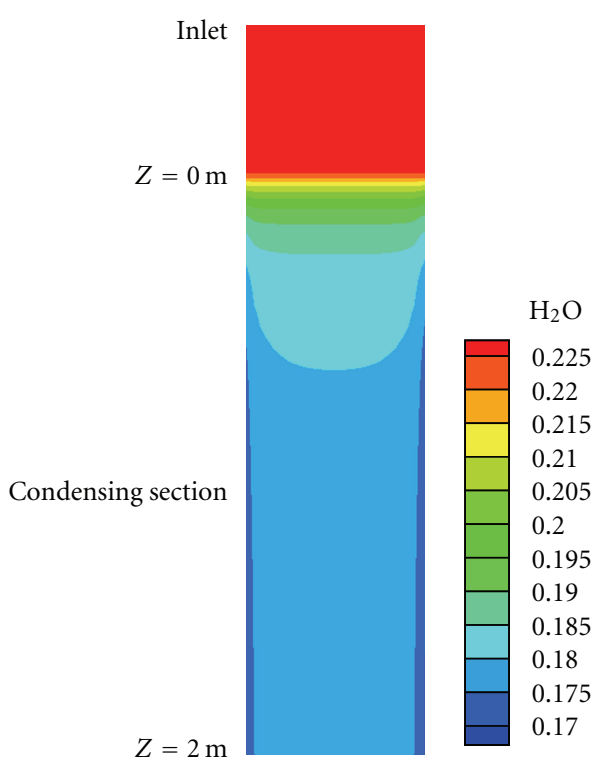

Figure 2: Steam mass fraction on the condensing wall for test P0444.

\section{Results and Discussion}

Figure 2 depicts the steam mass fraction on the layer of cell adjacent to the condensation wall for the test P0441. Figures $3,4,5$, and 6 show the condensation flux at wall along the height in the condensing section for all the steady states. The amount of steam condensed (numerically estimated) is slightly overestimated in the case of free convective heat transfer (P0443) experimental data by the proposed fit and proposed Nusselt (Lee corrected); however, it was in good agreement in case of natural convection with lower velocity (P0444, P0344) and with forced convection (P0441) against experimental data. Use of individual empirical correlation predicted numerical results are expectedly different as compared to the experimental data. The proposed fit is derived from various experimental conditions and the parameters which reduce the uncertainty and ensure the consistent applicability of the correlation irrespective of the parameter ranges. The present fit has been derived taking a fixed value of liquid film thickness and temperature gradient. However this can be improved based on specific requirement, and inputs can be generated for complex intercompartmental configurations within CFD framework. This result also advocates the replacement of simplified condensation model (lumped

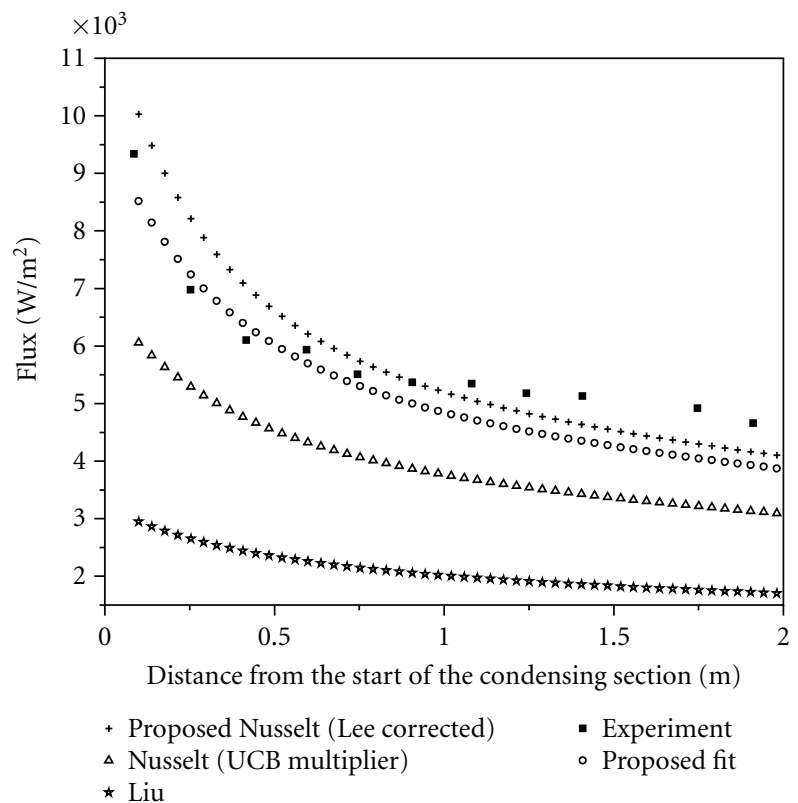

FIgURE 3: Variation of condensation flux with height, test P0441.

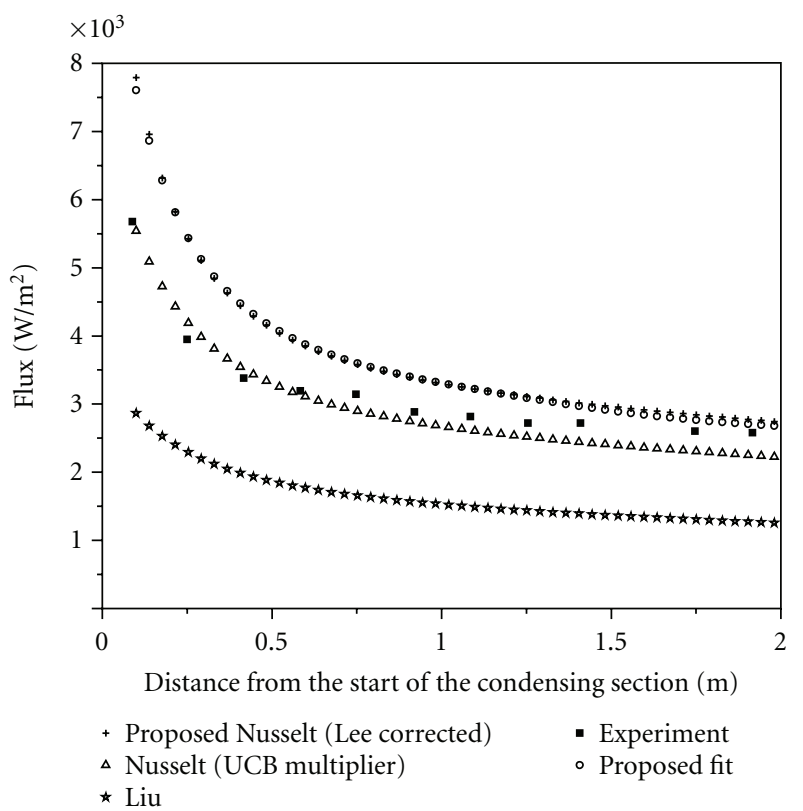

FIgURE 4: Variation of condensation flux with height, test P0443. 


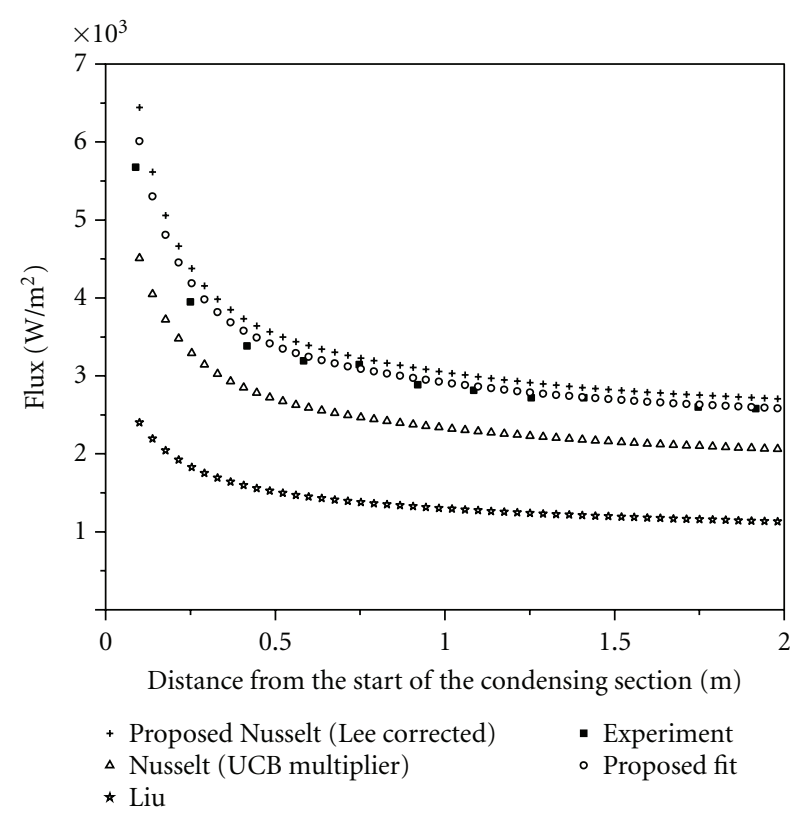

Figure 5: Variation of condensation flux with height, test P0444.

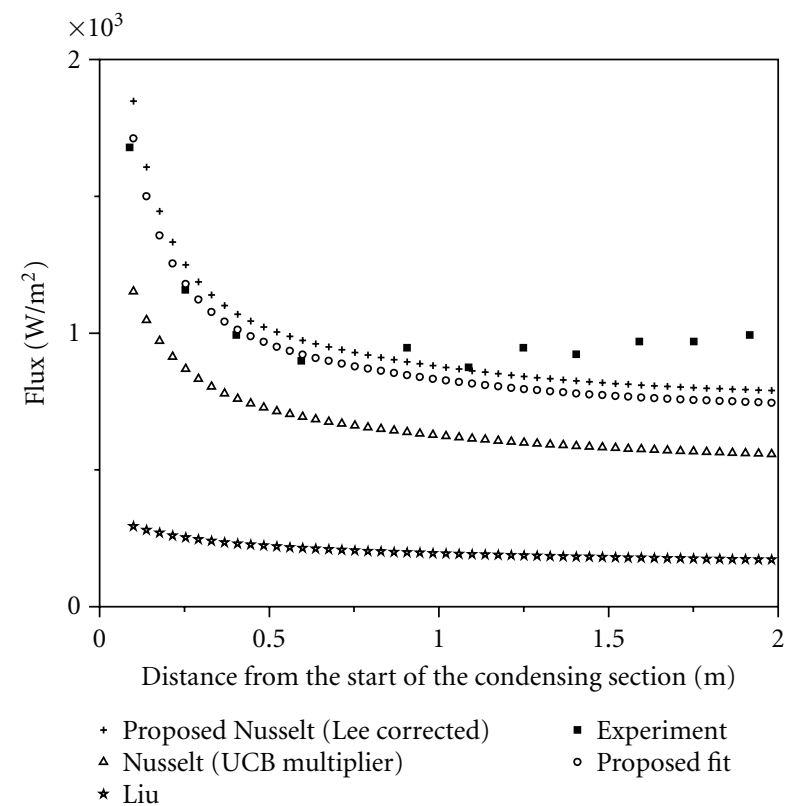

Figure 6: Variation of condensation flux with height, test P0344.

parameter code-like approach) with a new improved simple HTC in CFD-based approach which can be used to model real large containment geometry for safety evaluation in a more consistent manner.

\section{Conclusions}

A model for steam condensation was implemented and tested based on various correlations developed for volumeaveraged approach in the computational fluid dynamics code
CFD-ACE+. The CFD code CFD-ACE+ was used to simulate condensation experiments that were performed in the COPAIN facility. There was a reasonable agreement between simulated and experimental results for proposed approach derived from fitting of various experimental data. However further validations are needed against other experimental data. This approach does not solve the phenomenon from the first principle, but this approach can be considered as effective for industrial problem where solution for large computational domain is required. The present work suggests that the approach could be used for integrated hydrogen distribution/management calculation with steam condensation in nuclear reactor containment required for safety analysis. Another useful application of the present approach could be to obtain a first-order simplified generalized analysis result for a containment wall surface, and subsequently different wall surfaces can be studied in detail where specific correlations can be used within the CFD framework.

\section{Nomenclature}

$\begin{array}{ll}\phi: & \text { General transport variable } \\ \Gamma_{\phi}: & \text { Diffusion coefficient for variable } \phi \\ S_{\phi}: & \text { Source term for variable } \phi \\ m^{0}: & \text { Steam condensation rate }(\mathrm{kg} / \mathrm{s}) \\ \rho_{\text {steam }}: & \text { Density of steam }\left(\mathrm{kg} / \mathrm{m}^{3}\right) \\ \rho_{\text {nc }}: & \text { Density of noncondensible gases }\left(\mathrm{kg} / \mathrm{m}^{3}\right) \\ A: & \text { Area of condensation surface }\left(\mathrm{m}^{2}\right) \\ T: & \text { Temperature }(\mathrm{K}) \\ T_{\text {wall }}: & \text { Average temperature of condensation surface }(\mathrm{K}) \\ h_{f g}: & \text { Latent heat of steam }(\mathrm{J} / \mathrm{kg}) \\ H^{0}: & \text { Enthalpy sink due to condensation }(\mathrm{W}) \\ C_{p, \text { steam }}: & \text { Specific heat of steam at constant pressure }(\mathrm{J} / \mathrm{kgK}) \\ C_{p, \text { air }}: & \text { Specific heat of air at constant pressure }(\mathrm{J} / \mathrm{kgK}) \\ T_{\text {ref }}: & \text { Reference temperature }(\mathrm{K}) \\ P: & \text { Pressure }(\mathrm{Pa}) \\ B, C, D: & \text { Constants. }\end{array}$

\section{References}

[1] P. Royl, H. Rochholz, W. Breitung, J. R. Travis, and G. Necker, "Analysis of steam and hydrogen distributions with PAR mitigation in NPP containments," Nuclear Engineering and Design, vol. 202, no. 2-3, pp. 231-248, 2000.

[2] M. Houkema, N. B. Siccama, J. A. L. Nijeholt, and E. M. J. Komen, "Validation of the CFX4 CFD code for containment thermal-hydraulics," Nuclear Engineering and Design, vol. 238, no. 3, pp. 590-599, 2008.

[3] M. Babić, I. Kljenak, and B. Mavko, "Prediction of light gas distribution in experimental containment facilities using the CFX4 code," Nuclear Engineering and Design, vol. 238, no. 3, pp. 538-550, 2008.

[4] I. Kljenak, M. Babić, B. Mavko, and I. Bajsić, "Modeling of containment atmosphere mixing and stratification experiment using a CFD approach," Nuclear Engineering and Design, vol. 236, no. 14-16, pp. 1682-1692, 2006.

[5] I. Kljenak, I. Bajsić, and M. Babić, "Modelling of steam condensation on the walls of a large enclosure using a 
Computational Fluid Dynamics code," in Proceedings of the ASME-ZSIS International Thermal Science Seminar II, Slovenia, June 2004.

[6] H. Uchida, A. Oyama, and Y. Togo, "Evaluation of postincident cooling systems of LWRs," in Proceedings of the 13th International Conference on Peaceful Uses of Atomic Energy, pp. 93-102, International Atomic Energy Agency, Vienna, Austria, 1965.

[7] J. M. M. Valdepenas, M. A. Jimenez, F. M. Fuertes, and J. A. Fernandez, "Improvements in a CFD code for analysis of hydrogen behaviour within containments," Nuclear Engineering and Design, vol. 237, pp. 627-647, 2007.

[8] H. Terasaka and A. Makita, "Numerical analysis of the PHEBUS containment thermal hydraulics," Journal of Nuclear Science and Technology, vol. 34, no. 7, pp. 666-678, 1997.

[9] S. Mimouni, A. Foissac, and J. Lavieville, "CFD modelling of wall steam condensation by a two-phase flow approach," $\mathrm{Nu}$ clear Engineering and Design, vol. 241, no. 11, pp. 4445-4455, 2011.

[10] S. Kudriakov, F. Dabbene, E. Studer et al., "The TONUS CFD code for hydrogen risk analysis: physical models, numerical schemes and validation matrix," Nuclear Engineering and Design, vol. 238, no. 3, pp. 551-565, 2008.

[11] CFD-ACE+ V2009.2, User Manual, ESI CFD Inc., Huntsville, Ala, USA, 2009.

[12] J. Green and K. Almenas, "An overview of the primary parameters and methods for determining condensation heat transfer to containment structures," Nuclear Safety, vol. 37, no. 1, pp. 26-48, 1996.

[13] J. C. de la Rosa, A. Escriva, L. E. Herranz, T. Cicero, and J. L. Muñoz-Cobo, "Review on condensation on the containment structures," Progress in Nuclear Energy, vol. 51, no. 1, pp. 3266, 2009.

[14] K. Y. Lee and M. H. Kim, "Experimental and empirical study of steam condensation heat transfer with a noncondensable gas in a small-diameter vertical tube," Nuclear Engineering and Design, vol. 238, no. 1, pp. 207-216, 2008.

[15] M. Kawakubo, M. Aritomi, H. Kikura, and T. Komeno, "An Experimental Study on the Cooling Characteristics of passive containment cooling systems," Journal of Nuclear Science and Technology, vol. 46, no. 4, pp. 339-345, 2009.

[16] H. S. Park, H. C. No, and Y. S. Bang, "Assessment of two wall film condensation models of Relap/Mod3.2 in the presence of noncondensable gas in a vertical tube," Journal of the Korean Nuclear Society, vol. 31, pp. 465-475, 1999.

[17] X. Cheng, P. Bazin, P. Cornet et al., "Experimental data base for containment thermalhydraulic analysis," Nuclear Engineering and Design, vol. 204, no. 1-3, pp. 267-284, 2001. 

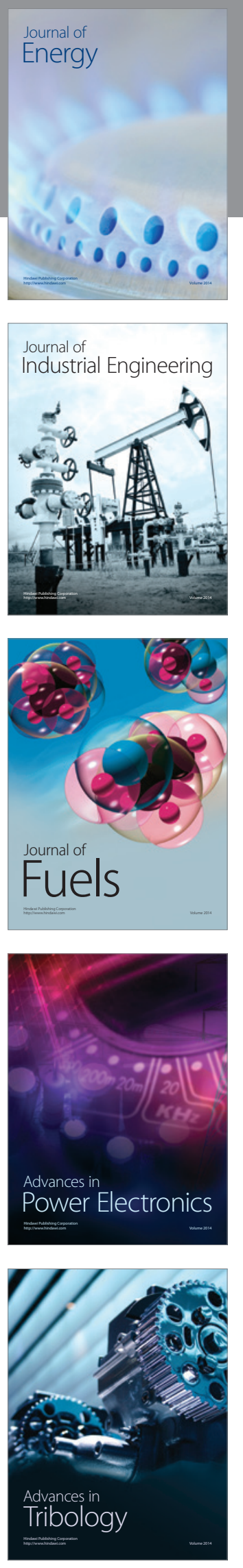
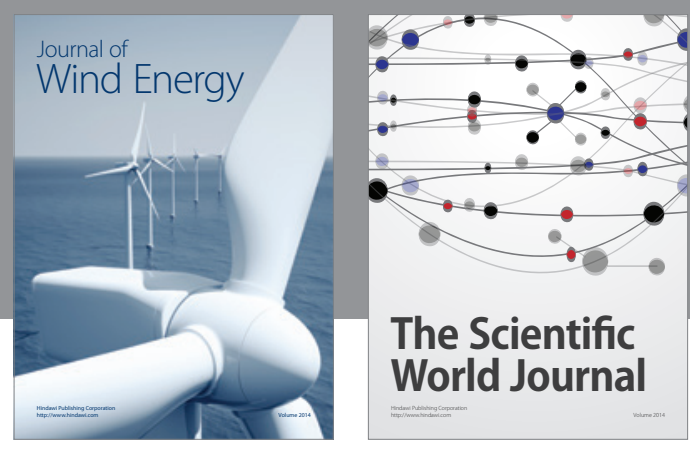

The Scientific World Journal

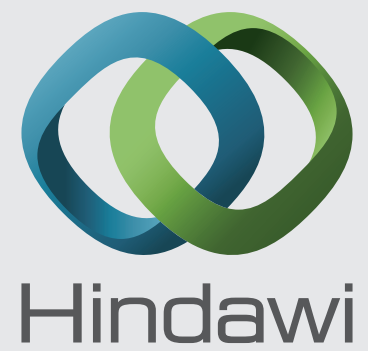

Submit your manuscripts at http://www.hindawi.com
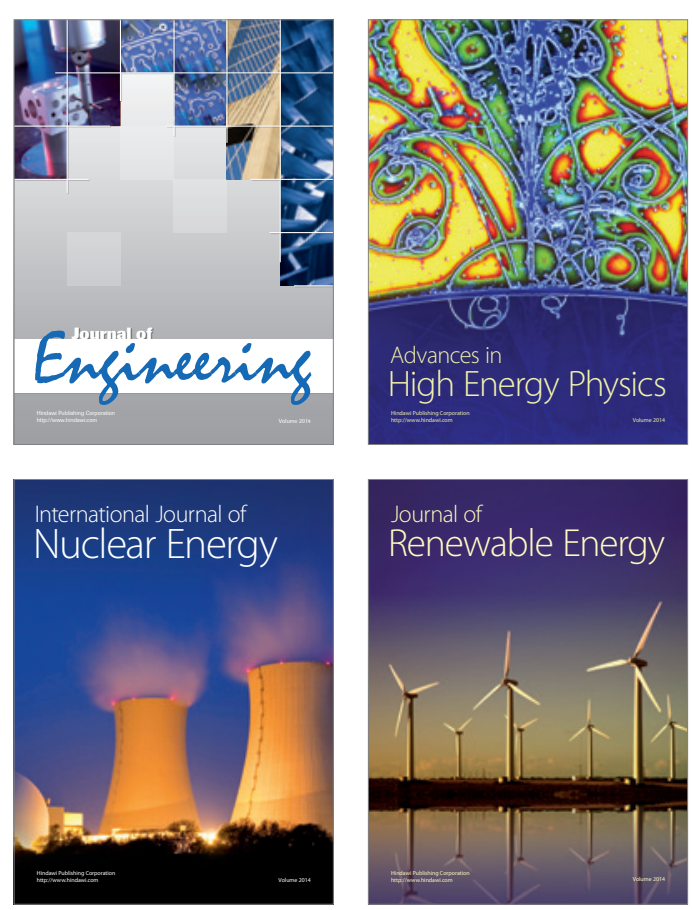

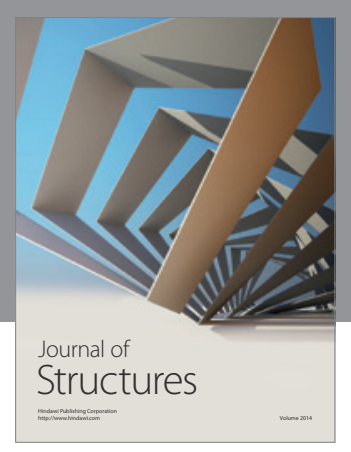

Rotating
Mechinery
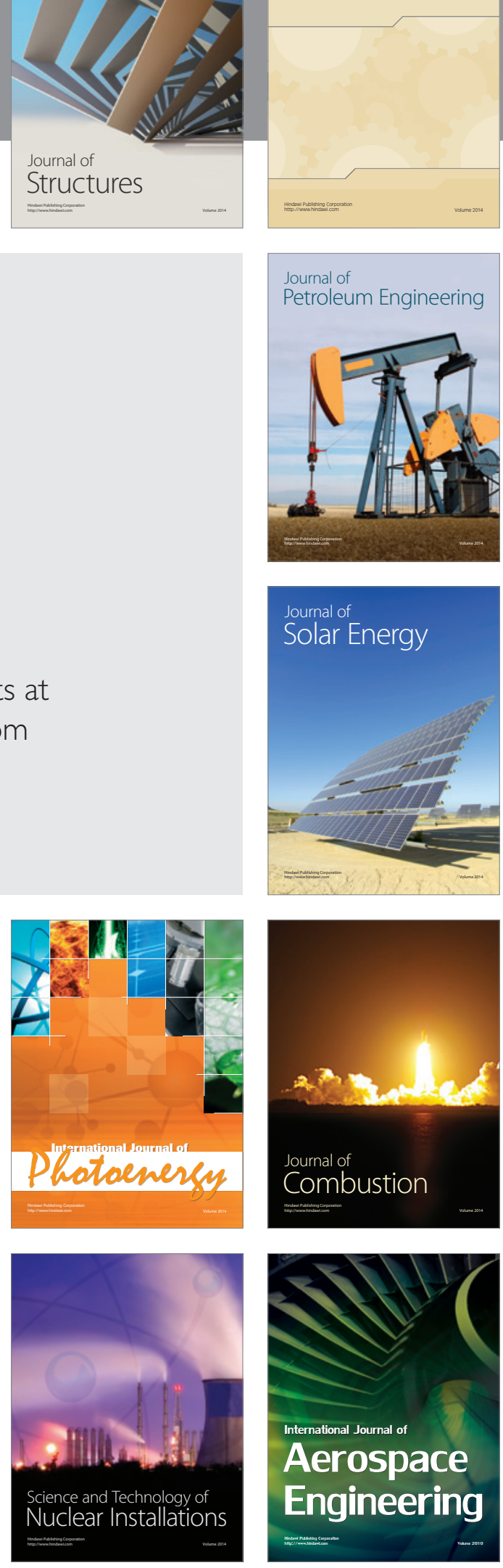